\title{
A Necessidade da Formação de Gestores no Seror Público: Análise das unidades do Poder Judiciário do Estado da Bahia no Território de Identiadade da Bacia do Jacuípe
}

\author{
Erika da Cruz Gonçalves Noberto ${ }^{l}$; Gilbert Santos da Silva ${ }^{l}$; Jessé Roberto Matos da Silva ${ }^{2}$; \\ Manuela Pereira Sampaio de Souza ${ }^{1}$; Hesler Piedade Caffé Filho ${ }^{3}$
}

\begin{abstract}
Resumo: A presente pesquisa trata sobre as dificuldades enfrentadas pelos administradores dos fóruns do Território de Identidade da Bacia do Jacuípe do Estado da Bahia, especificamente no que concerne a ausência de capacitação na área de gestão pública. Esclarece sobre a necessidade de especialização para os diversos profissionais, principalmente no que diz respeito aos que lidam com a gestão pública e analisa a existência de programa de aprimoramento ou incentivo à formação acadêmica pelo Poder Judiciário do Estado da Bahia. Como método de pesquisa foram distribuídos questionários indagando sobre a formação acadêmica dos referidos auxiliares da justiça, oferecimento de cursos de capacitação e aprimoramento por parte do Tribunal de Justiça do Estado da Bahia, dificuldades enfrentadas no desempenho das funções, entre outras questões relevantes para análise da problemática. Posteriormente, os resultados foram analisados sob a ótica da literatura que defende a necessidade e importância da formação e capacitação dos gestores públicos para que a prestação de serviços eficiente e eficaz seja alcançada.
\end{abstract}

Palavras-chave: Administrador do Fórum. Capacitação. Formação específica. Gestão.

\section{The Need For Training Managers In The Public Sector: analysis of the units of the Judiciary Branch of the State of Bahia in the Identity Territory of the Jacuípe Basin}

\begin{abstract}
The present research deals with the difficulties faced by the administrators of the forums of the Identity Territory of the Jacuípe Basin of the State of Bahia, specifically in what concerns the lack of training in the area of public management. Clarifies on the need for specialization for the various professionals, especially those that deal with public management and analyzes the existence of a program to improve or encourage academic training by the Judicial Branch of the State of Bahia. As a research method, questionnaires were distributed inquiring about the academic training of the aforementioned legal assistants, offering training and improvement courses on the part of the Court of Justice of the State of Bahia, difficulties encountered in the performance of their duties, among other issues relevant to the analysis of Problematic. Subsequently, the results were analyzed from the perspective of the literature that defends the need and importance of the training and qualification of the public managers so that the efficient and effective provision of services is achieved.
\end{abstract}

Keywords: Forum Administrator. Training. Specific training. Management.

\section{Introdução}

Diante das constantes transformações vivenciadas pela sociedade, que coexiste com a globalização, tecnologia da informação, mudanças aceleradas, imprevisibilidade, instabilidade e incerteza.

\footnotetext{
${ }^{1}$ Curso de Administração Pública. Universidade Federal do Vale do São Francisco, UNIVASF, Brasil.

${ }^{2}$ Graduação em Letras: Língua Portuguesa e suas Literaturas pela Universidade Norte do Paraná. Curso de Administração Pública. Universidade Federal do Vale do São Francisco, UNIVASF, Brasil;

${ }^{3}$ Mestrado Profissional em Mestrado em Gestão de Políticas Públicas pela Universidade Federal do Recôncavo da Bahia, Brasil. Professor de Pós Graduação EaD da Universidade Federal do Vale do São Francisco, Brasil. Contato: hesler.caffe@ univasf.edu.br.
} 
Cada vez mais é exigida uma boa prestação de produtos e serviços, com eficiência e eficácia, tornando-se imprescindível o investimento na gestão.

Nas organizações públicas, a função essencial é a prestação de serviços, com a finalidade de alcance do bem comum. No caso do Poder Judiciário, o alvo é oferecer uma jurisdição de qualidade, resolvendo os conflitos. No entanto, nos deparamos com várias situações adversas, que atrapalham o alcance deste objetivo, gerando lentidão e queda na qualidade dos serviços, frustrando a sociedade. Entre tais circunstâncias, podemos destacar a ausência da formação específica em gestão pública por parte dos auxiliares da justiça responsáveis pela administração das unidades judiciárias, que na Bahia são aqueles que ocupam o cargo de "administrador do fórum".

Os administradores dos fóruns ingressam no serviço público por meio de concurso público de provas, cuja exigência de escolaridade é a de nível superior, sem especificação do curso. Dentre as suas responsabilidades estão as típicas de gestão, tais como: requisitar, receber e guardar material; zelar pela limpeza e conservação dos móveis e utensílios afetos a Administração; manter o edifício do Fórum aberto e em condições de funcionamento; exercer fiscalização sobre as dependências e os pertences do edifício do Fórum, inclusive no que se refere ao comportamento das pessoas que o frequentam ou nele trabalham; auxiliar os Juízes na manutenção, disciplina e fiscalização do Fórum; além daquelas atinentes a gestão orçamentária descentralizada, como licitação, empenho e liquidação de pagamentos.

Como dito, apesar da nomenclatura do cargo, não há exigência de formação na área de gestão pública para o exercício da função, nem posterior oferecimento de capacitação na área, o que, por certo, dificulta o trabalho destes servidores e reflete diretamente na prestação de serviço ao público, seja por conta da simples ausência do devido controle de material que pode resultar na suspensão dos serviços ou até pela dificuldade em gerir adequadamente os demais servidores (gestão de pessoas).

É por este motivo, dentre outros, que a Constituição Federal aponta para a necessidade de investimento em gestão no serviço público, principalmente ao incluir entre os princípios da administração pública o princípio da eficiência. 
Diante desse quadro, urge a exigência da especialização dos administradores dos fóruns, a fim de que lidem adequadamente com as diversas demandas gerenciais que lhe são propostas cotidianamente, resultando num trabalho mais eficiente.

Por tudo isso, decidimos pesquisar a respeito das dificuldades enfrentadas pelos administradores dos fóruns do Território de Identidade da Bacia do Jacuípe do Estado da Bahia, especificamente no que concerne a ausência de capacitação na área de gestão pública.

\section{Procedimentos metodológicos}

Como método de pesquisa, foram distribuídos questionários indagando sobre a formação acadêmica dos referidos auxiliares da justiça, oferecimento de cursos de capacitação e aprimoramento por parte do Tribunal de Justiça do Estado da Bahia, dificuldades enfrentadas no desempenho das funções, entre outras questões relevantes para análise da problemática. Posteriormente, analisamos os resultados, sob a ótica da literatura que defende a necessidade e importância da formação e capacitação dos gestores públicos para que a prestação de serviços eficiente e eficaz seja alcançada.

Com isso, buscamos analisar se a ausência de formação em gestão pública por parte dos administradores dos fóruns do Poder Judiciário no Estado da Bahia afeta a eficiência dos serviços prestados, ao mesmo tempo que visamos esclarecer sobre a necessidade de especialização para os diversos profissionais, principalmente no que diz respeito aos que lidam com a gestão pública; analisar a existência de programa de aprimoramento ou incentivo à formação acadêmica pelo Poder Judiciário do Estado da Bahia e pesquisar a respeito das dificuldades enfrentadas pelos administradores dos fóruns em razão da inadequada formação acadêmica e/ou capacitação profissional.

A pesquisa realizada é exploratória, no que se refere aos objetivos, pois busca familiarizar-se com um assunto ainda pouco conhecido, pouco explorado. Já no que tange à abordagem, a pesquisa é qualitativa, porque a preocupação é com aspectos da realidade que não podem ser quantificados, de modo a centrar-se na compreensão e explicação da dinâmica de determinada relação social. 
A pesquisa trabalhará com um universo de significados, motivos, aspirações, crenças, valores e atitudes, o que corresponde a um espaço mais profundo das relações, dos processos e dos fenômenos que não podem ser reduzidos à operacionalização de variáveis.

Assim, partindo de tais pressupostos, foram entregues questionários aos administradores dos fóruns dos municípios baianos que compõem o Território de Identidade da Bacia do Jacuípe (Baixa Grande, Capela do Alto Alegre, Capim Grosso, Gavião, Ipirá, Mairi, Nova Fátima, Pé de Serra, Pintadas, Quixabeira, Riachão do Jacuípe, São José do Jacuípe, Serra Preta, Várzea da Roça e Várzea do Poço), indagando sobre a formação acadêmica dos referidos servidores, a opinião sobre a importância de formação específica na área de administração para exercer as funções do cargo, o oferecimento de cursos e treinamento por parte do empregador, entre outros questionamentos.

\section{A importância da qualificação em Gestão Pública}

Muito se tem falado em gestão pública e da necessidade de profissionais qualificados em tal área, almejando-se que com o aumento de gestores preparados e com conhecimento adequado, as atividades do setor público consigam se deslanchar e atravessar barreiras burocráticas, de forma que os aspectos relacionados à necessidade de qualificação e profissionalização da administração pública passem a compor a agenda de prioridades da gestão pública em todas as esferas do poder público. A qualificação da gestão pública passa a ser compreendida como condição para prover serviços públicos de melhor qualidade.

Com este enfoque é que começaram a surgir os programas de qualificação dos servidores públicos, nos diferentes níveis da administração pública. Já no final dos anos noventa, GAETANI (1998) destacava os desafios que se colocavam à formação dos gestores públicos, principalmente no contexto que se referia à incorporação da ênfase gerencial nos processos de qualificação, apontando como alternativas, por exemplo, o treinamento no serviço, o ensino a distância, o suporte de monitores, a interação via internet, entre outros.

Foi exatamente por isso que no plano federal, inaugurou-se um novo contexto de investimento em capacitação, com a publicação da Política Nacional de Capacitação (Decreto n. 2.794/1998), cujas finalidades buscaram garantir a valorização do servidor por meio da 
capacitação, a necessidade de atualização profissional e o desenvolvimento de servidores associado aos objetivos institucionais.

Na mesma toada, em 2006, foi publicado o Decreto n. 5.707, de 23 de fevereiro, que instituiu a Política Nacional de Desenvolvimento de Pessoal (PNDP), voltada a todos os órgãos e entidades da Administração Pública Federal (APF) direta, autárquica e fundacional, constituindo-se como um grande marco do fortalecimento da capacitação dos servidores públicos (DEMARCO; DONAZAR; BARRETO, 2014).

Faz-se importante destacar que, apesar dos atos normativos mencionados serem direcionados para os servidores públicos da Administração Federal, houve grande repercussão das suas diretrizes nas demais esferas administrativas, quando diversos estados e municípios incorporaram seus princípios organizadores na gestão de pessoas, especialmente nos setores responsáveis pelas políticas de qualificação. Houve incremento das demandas por novas atividades formativas, tanto de cursos livres, instrumentais, como, sobretudo àquelas em nível de especialização lato sensu.

Nesse contexto foi que surgiu, em 2009, o PNAP com o objetivo de contribuir para a formação de "[...] profisssionais com amplo conhecimento em administração pública, capazes de atuar no âmbito federal, estadual e municipal, administrando com competência e ética as organizações governamentais e não-governamentais.” (FERREIRA, 2013).

Ocorre, entretanto, que mesmo diante de todo esse quadro de crescente investimento na formação, qualificação e especialização dos servidores públicos, o poder judiciário tem ficado alheio, a exemplo do que ocorre no Estado da Bahia, onde os fóruns são administrados por servidores cujo cargo recebem a nomenclatura "Administrador do Fórum", possuem responsabilidades correlatas à de gestão, mas não lhes é exigida a formação específica na área de administração, muito menos na de gestão pública, não sendo, ainda, fornecidos cursos de atualização em tal área.

A propósito veja-se o que dispõe o art. 255, da Lei Estadual n. 10.845, de 27 de novembro de 2007, a qual dispõe sobre a Organização Judiciária do Estado da Bahia:

\section{DO ADMINISTRADOR DO FÓRUM}

Art. 255 - Incumbe ao Administrador do Fórum nas Comarcas do Interior: I - requisitar, receber e ter sob sua guarda o material de expediente do Juízo, zelando pela limpeza e conservação dos móveis e utensílios necessários ao serviço forense; 
II - manter o edifício do Fórum aberto e em condições de funcionamento, nos dias e no horário do expediente;

III - exercer fiscalização sobre as dependências e os pertences do edifício do Fórum, inclusive no que se refere ao comportamento das pessoas que o frequentam ou nele trabalham, trazendo ao conhecimento do Juiz, ou a quem couber a sua direção, todos os fatos que lhe pareçam contrários à ordem e aos bons costumes;

IV - afixar e recolher editais;

V - receber e distribuir a correspondência destinada aos Juízes, ao Promotor de Justiça e servidores;

VI - auxiliar os Juízes na manutenção, disciplina e fiscalização do Fórum.

De tais atribuições se extrai que o administrador do fórum desempenha funções análogas à de gestão, tais como de gestão de material e gestão de pessoas. Entretanto, de acordo com o $\S 2^{\circ}$, do art. 208, da mesma lei acima mencionada, para o referido cargo é exigida apenas s formação em ensino superior, sem especificação de curso.

Esta situação, sem dúvidas, vai de encontro com a exigência imposta pela realidade social atual de que haja gestores devidamente capacitados e qualificados em todos os setores, seja público ou privado.

E isso tem sido uma alerta constante, tanto que os juízes Carlos Eduardo Mattioli Kockanny e Luiza Vieira Sá de Figueiredo, num artigo intitulado “Gestão no Poder Judiciário e novos paradigmas", disponível em

www.amb.com.br/index2014.asp?secao=artigo_detalhe\&art_id=1945>, afirmam:

O principal recurso de um tribunal são pessoas, e a Reforma do Judiciário passa, sem sombra de dúvidas, pela capacitação de seus membros para a nova realidade experimentada pela sociedade. É preciso, portanto, que os tribunais desenvolvam inteligência administrativa sustentada e não se conformem com "inteligências pontuais compradas no varejo". É preciso que o Judiciário assuma sua capacidade constitucional de autogestão através da capacitação de seus membros.

Tratando especificamente sobre as dificuldades enfrentadas pelo Poder Judiciário, SERRA (1996), assim descreveu o quadro:

Em princípio, as críticas relativas à morosidade formuladas ao Poder Judiciário pareciam injustas, se analisadas do ponto de vista do próprio Poder, pois tinham conhecimento das dificuldades encontradas por seus integrantes. A atuação do Judiciário como prestador de serviços era deficiente e deixava de apontar que não eram aplicadas técnicas de gestão. Destacava-se que a maior parte das serventias autuavam acima dos limites de suas capacidades produtivas, sofriam de uma sistemática carência de investimentos em organização, layout e de informática, e as estatísticas exibiam números grandiosos de demanda. Após alguma análise diagnóstica, pôde-se perceber que ocorria manifesta a ausência de uma política 
pública, clara, transparente, objetiva, de contratação e movimentação de pessoal, de treinamento específico dos servidores para o desempenho de suas atividades, de treinamento para o atendimento ao público, que levasse ao aprimoramento dos serviços prestados, visando torná-los mais simplificados, ao alcance e de fácil compreensão por aqueles de menor preparação técnica ou intelectual.

O administrador do fórum, conforme visto mais acima, é o servidor que deveria, através da gestão adequada de material e de pessoas, facilitar o trabalho dos demais servidores do judiciário. Todavia, para isso, é indispensável sua capacitação e formação adequada para que, assim, possa desempenhar de forma eficaz as responsabilidades inerentes ao cargo.

A propósito, Carlos Roberto Faleiros Diniz, no artigo "Gestão Administrativa e Reforma do Poder Judiciário”, disponível em http://www.oabsp.org.br/noticias/2003/05/08/1826>, afirma:

(...) o caminho a ser seguido não pode ser outro senão o da inserção de técnicas de gestão administrativa a serem observadas pelos operadores do Judiciário. Indispensável e impostergável que se retome a eficiência do Poder Judiciário, sendo certo que a eficiência, nesse caso, se mede através do dinamismo e da liquidez com que o serviço judiciário é prestado. Isso será possível através da adoção de programas que visem dotar de maior racionalidade a organização judicial, trabalhando sobre elas, concentrando recursos e envidando esforços de todos .

Dentro deste arco de caminhos, é possível destacar como tópicos de uma reforma administrativa a programação, a utilização e o controle administrativo dos meios materiais e humanos precisos para a atuação das varas e tribunais de justiça; a aquisição de materiais suficientes para o exercício das atividades cotidianas, bem como de móveis e imóveis necessários para aprimorar a prestação de serviços; a elaboração de projetos visando a construção de novas instalações judiciais, que abriguem todos os volumes de processos e o número de funcionários necessários para desenvolver o trabalho de forma racionalizada; uma rígida fiscalização financeira, através de comprovação de contas e gastos com o funcionamento, dentre outros. Acima de tudo, imprescindível que à frente de todas essas medidas estejam agentes públicos capazes de liderar a transição para um modelo de gestão judiciária organizada, o que pressupõe uma capacidade nata para atuar com firmeza diante da desorganização material e institucional que impera.

Tudo isso aponta para a importância do papel do administrador do fórum para o bom andamento da própria prestação jurisdicional. Mas, infelizmente, não se tem dado a atenção devida para tal problemática.

\section{Resultados e discussões}


Após aplicação dos questionários e análise das respostas já tabuladas, foi possível refletir e interpretar os dados visando atingir o objetivo geral da pesquisa. Percebeu-se logo de início que a necessidade de investimento em treinamento e formação dos administradores dos fóruns do Poder Judiciário Baiano é urgente.

Dos quinze administradores de fóruns que responderam os questionários, apenas quatro possuem formação em nível superior, sendo que nenhum deles fez pós-graduação, nem é graduado em Administração ou outro curso relacionado a gestão pública ou privado.

Quando indagados sobre a importância de formação específica na área de administração para exercer as funções inerentes ao cargo de Administrador do Fórum, unanimemente responderam que a formação específica é de grande relevância, pois no cotidiano enfrentam inúmeras dificuldades relacionadas exatamente a ausência de preparo teórico para lidarem, por exemplo, com a gestão financeira que, no âmbito do Poder Judiciário do Estado da Bahia, é descentralizada, de modo que cada Comarca é uma Unidade Gestora. Apontaram, ainda, que desde a assunção do cargo/função nunca receberam treinamento específico relativa a área de administração ou gestão e que o empregador não fornece incentivos financeiros ou convênios para formação acadêmica dos servidores ocupantes do cargo de Administrador do Fórum.

Por fim, quando questionados se o trabalho desenvolvido pelo Administrador do Fórum reflete na celeridade do andamento dos processos em trâmite nas Unidades Judiciais, responderam, em geral, que as dificuldades enfrentadas na Administração do Fórum atrapalham na prestação jurisdicional porque a falta de material permanente e de expediente, as falhas na gestão de pessoas e a própria inadequação das instalações físicas acabam por obstaculizar o trabalho dos servidores da atividade fim que lidam diretamente com os processos judiciais.

Logo, é claro que a ausência de formação e capacitação dos Administradores dos Fóruns nas áreas de gestão acaba por refletir negativamente na prestação jurisdicional, surgindo como alternativa de enfrentamento do problema, a o investimento na atividade-meio - gestão - para, por meio de servidores capacitados e, consequentemente, motivados, valorizados e satisfeitos, atingir-se com eficácia e eficiência a atividade-fim - distribuição da justiça. 
Dessa forma, é necessário o desenvolvimento de modernas técnicas de administração, por meio da capacitação e formação dos servidores, inclusive na gestão de pessoas, no âmbito de cada unidade jurisdicional para a melhoria da prestação dos serviços.

Certamente, com a formação específica dos servidores responsáveis pela Administração dos Fóruns, estar-se-ia investindo, de forma reflexa, na inovação, já que, assim, presume-se que haveria melhor utilização dos recursos materiais e humanos disponíveis para que, alfim, seja atingido o resultado almejado, ou seja, a qualificada e célere prestação jurisdicional.

\section{Considerações finais}

Há muito tempo a mídia tem noticiado as dificuldades enfrentadas pelo Judiciário para gerir e julgar com celeridade as demandas que lhe são levadas à apreciação. A partir do presente estudo, constatou-se que, ao menos no âmbito das unidades analisadas, este problema tem, também, como casuística, a ausência da formação específica dos administradores dos fóruns. Isso, resulta, por exemplo, em varas mal aparelhadas, sem os equipamentos necessários para o encaminhamento rápido dos processos; funcionários mal gerenciados; espaço pequeno para a quantidade de trabalho que diariamente se avoluma; falta de fiscalização constante por parte dos chefes e responsáveis pelo andamento da repartição.

Nota-se, portanto, que o papel do Administrador do Fórum é de primordial importância para a atividade-fim desenvolvida pelo Poder Judiciário, sendo imperiosa a adequada formação e capacitação destes servidores para que possam desempenhar eficientemente as funções inerentes ao cargo.

Verificou-se, ainda, que, pelo menos no âmbito das Unidades do Poder Judiciário alocadas no Território de Identidade da Bacia do Jacuípe do Estado da Bahia, os administradores do fórum não possuem formação em gestão e o empregador não tem investido para mudar tal realidade, o que acaba por refletir negativamente na prestação jurisdicional.

Urge, então, a alteração desta realidade e para que ocorra a mudança desse cenário, há necessidade que se assuma de uma vez por todas que para desempenhar eficientemente a 
função de administrador do fórum, de forma eficiente e eficaz, é necessário uma gama de conhecimentos de gestão e gerência administrativa. Não basta a informatização dos processos, nem reformar procedimentos se as unidades não estão sendo bem geridas e se os administradores desconhecem as principais técnicas de gestão administrativa.

Faz-se necessário desenvolver um Programa Permanente de Capacitação e Desenvolvimento dos Servidores, principalmente dos que desempenham funções relacionadas a atividades administrativas, visando desenvolver conhecimentos, atitudes e habilidades, objetivando que tais servidores, tantos os novos como os antigos, dominem as modernas técnicas de gestão e administração, se tornando mais produtivos, criativos e inovadores.

Nesse ponto, importante transcrever o pensamento de Chiavenato (2004):

O treinamento não deve ser confundido com uma simples questão de realizar cursos e proporcionar informação. Vai muito mais longe. Significa atingir o nível de desempenho almejado pela organização através do desenvolvimento continuo das pessoas que nela trabalham. Para tanto, é desejável criar e desenvolver uma cultura interna favorável ao aprendizado e comprometida com as mudanças na organização.

Tal é a importância do treinamento que a Constituição Federal, por meio da Emenda Constitucional n. 19 de 1998, prevê a manutenção de escolas para formação e aperfeiçoamento de servidores e aplicação de recursos orçamentários para treinamento de pessoal, de modo a reforçar a importância da formação dos servidores, mormente no caso estudado, onde se revelou fundamental o treinamento e capacitação dos administradores dos fóruns para que desempenhem adequadamente as funções inerentes ao cargo e, por conseguinte, contribuam para a melhoria da prestação jurisdicional.

\section{Referências}

BAHIA. Assembleia Legislativa. Lei Estadual n. 10.845, de 27 de novembro de 2007. Disponível em: < http://www.legislabahia.ba.gov.br/>. Acesso em: 27 jun. 2017.

BRASIL. Decreto n. 5.707, de 23 de fevereiro de 2006. Diário Oficial [da] República Federativa do Brasil, Brasília, 24 fev. 2006, Seção 1, p. 3.

CHIAVENATO, Idalberto. Gestão de pessoas. 2. ed. Rio de Janeiro: Elsevier, 2004. 
DEMARCO, D. J.; DONAZAR, R. C. ; BARRETO, R. A. C. M. Políticas de capacitação e desenvolvimento de servidores: o caso da UFRGS. In: Calvete, Cássio da S.; Gosmann, Máris C.. (Org.). Políticas de emprego, trabalho e previdência. $1^{\mathrm{a}}$ ed. Porto Alegre: Editora da UFRGS, 2014, v. 1, p. 72-93.

FERREIRA, Marcello; MILL, Daniel. Institucionalização da educação a distância no ensino superior público brasileiro: desafios e estratégias. In: FIDALGO, Fernando Selmar Rocha et al. (Org.). Educação a distância: meios, atores e processos. Belo Horizonte: CAED-UFMG, 2013. p. 143-161.

GAETANI, Francisco. Capacitação de recursos humanos no serviço público: problemas e impasses. Brasília: ENAP, 1998. p. 27.

SERRA, Umpierre de Mello. Gestão de Serventias. v. 1. Rio de Janeiro: FGV, 1996. p. 7 e 8.

\section{Como citar este artigo (Formato ABNT):}

NOBERTO, Erika da C. G.; SILVA, Gilbert S.; SILVA, Jessé R.M.; SOUZA, Manuela P.S.; CAFFÉ FILHO, Hesler P. A Necessidade da Formação de Gestores no Seror Público: Análise das unidades do Poder Judiciário do Estado da Bahia no Território de Identiadade da Bacia do Jacuípe. Id on Line Revista Multidisciplinar e de Psicologia, Julho de 2017, vol.11, n.36, p.189-199. ISSN: 1981-1179.

Recebido: 27.06.2017

Aceito: 30.06 .2017 